\title{
Mechanism of cadmium poisoning on testicular injury in mice
}

\author{
YAPING REN $^{1 *}$, WENHUA SHAO $^{2,3^{*}}$, LIJUN ZUO $^{1 *}$, WEI ZHAO $^{1}$, HAIZHANG QIN $^{1}$, \\ YINGJIE HUA ${ }^{1}$, DEJIE LU ${ }^{1}, \mathrm{CHAO} \mathrm{MI}^{3}$, SIEN ZENG ${ }^{2,3}$ and LIAO ZU ${ }^{4}$ \\ ${ }^{1}$ Department of Histology and Embryology; ${ }^{2}$ Laboratory of Tumor Immunology and Microenvironmental Regulation; \\ ${ }^{3}$ Department of Pathology and Physiopathology, Guilin Medical University; ${ }^{4}$ Evidence Identification Center, \\ The Seven Star Branch in The Guilin City Public Security Bureau, Guilin, Guangxi 541004, P.R. China
}

Received February 24, 2018; Accepted March 15, 2019

DOI: $10.3892 / 01.2019 .10418$

\begin{abstract}
Cadmium is a heavy metal that is toxic to humans and the reproductive system. The present study aimed to investigate the mechanisms of cadmium-induced reproductive toxicity in a male Institute of Cancer Research mouse model of cadmium poisoning. Changes in luteinizing hormone receptor (LHR), 17 $\alpha$-hydroxylase and endothelial nitric oxide (NO) synthase (eNOS) expression levels were examined. A total of 24 male mice (4-week-old) were randomly divided into four groups (normal control group and low, medium and high cadmium groups) and subjected to gavage treatment with normal saline or cadmium-containing saline solutions for 8 weeks prior to sacrifice. To assess testicular injury, serum androgen levels were determined by ELISA, testicular tissue pathological changes were evaluated using hematoxylin and eosin staining. In addition, LHR, 17 $\alpha$-hydroxylase and eNOS expressions levels were examined by western blotting, and apoptosis was examined with a terminal deoxynucleotidyl transferase dUTP nick end labeling assay. The results demonstrated that the severity of testes injury increased with cadmium concentration. In addition, LHR, 17 $\alpha$-hydroxylase and eNOS expression levels increased with low and medium concentrations of cadmium; however, they were decreased following treatment with high concentrations of cadmium. The results from the present study demonstrated that cadmium altered LHR, 17 $\alpha$-hydroxylase and eNOS expression levels in testicular stromal cells, which may impact testosterone
\end{abstract}

Correspondence to: Professor Liao $\mathrm{Zu}$, Evidence Identification Center, The Seven Star Branch in The Guilin City Public Security Bureau, East Circle Road, Guilin, Guangxi 541004, P.R. China E-mail: 2350363204@qq.com

Professor Sien Zeng, Department of Pathology and Physiopathology, Guilin Medical University, 20 Lequn Road, Guilin, Guangxi 541004, P.R. China

E-mail: 963940998@qq.com

${ }^{*}$ Contributed equally

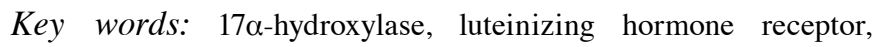
endothelial nitric oxide synthase, androgen, spermatogenesis synthesis. Furthermore, NO was suggested to be involved in cadmium-induced testicular injury by measurements of eNOS expression in testicular stromal cells.

\section{Introduction}

Over the past few decades, male infertility has increased (1), a phenomenon that is closely associated with environmental pollution (2). Particularly, cadmium is a highly toxic heavy metal that has been reported to induce male infertility $(3,4)$. With the rise of the incidence rate of infertility, the adverse effects of environmental factors are becoming an increasing concern. Particularly, environmental pollution has posed a serious threat in recent years. Guangxi is an area with high cadmium, which has an adverse effect on the safety of life $(1,3,4)$. Previous studies have demonstrated that the reproductive toxicity of cadmium is the highest, particularly in the male reproductive toxicity system (4-8). Human intake of cadmium primarily originates from the consumption of contaminated water, crops, cigarettes or other sources (9). Cadmium deposition in the kidney, bones, liver, lung and reproductive organs $(10,11)$ leads to severe organ impairment (12). Three mechanisms of cadmium-induced cellular injury have been proposed (5,13-16). The first concerns cadmium-calcium interactions, in which cadmium may enter cells through calcium channels and compete with calcium to bind calmodulin, interfering therefore with calmodulin and with calmodulin-dependent physiological and biochemical processes $(1,3)$. The second mechanism involves protein alterations. Particularly, cadmium may interact with the hydroxyl, mercapto and amino groups of proteins to generate cadmium-protein complexes, which can suppress or inactivate multiple enzyme systems, which can have a deleterious impact on biological activities (4). In the third mechanism, cadmium can influence the expression of apoptotic genes $(5,17)$. Cadmium can induce abnormal gene expression, inhibit DNA damage repair and cell apoptosis. Cadmium exposure increases the mRNA expression level of the pro-apoptotic Bax gene in the small intestine of rats and decreases the mRNA expression level of anti-apoptotic Bcl-2 gene. Thereby, it increases the $\mathrm{Bax} / \mathrm{Bcl}-2$ ratio and induces apoptosis of cells $(18,19)$. Testicular stromal cells are essentially responsible for testosterone synthesis (20). Testosterone secreted by Leydig cells is transported to target organs throughout the 
body via the blood circulation, and promotes differentiation and development of reproductive organs, development and maintenance of male secondary sexual characteristics, and sperm by binding to androgen receptors. It serves an important role in maintaining sexual function and promoting metabolism, including promotion of protein synthesis, bone growth and erythropoiesis $(21,22)$. Additionally, testosterone can enter Sertoli cells in a paracrine manner, and is involved in the regulation of spermatogenesis. When testosterone enters Sertoli cells, it serves the following four functions during spermatogenesis: i) Maintenance of blood-testis barrier; ii) regulation of meiosis; iii) maintenance of the adhesion between spermatozoa and Sertoli cells; and iv) regulation of the release of mature sperm $(23,24)$. Testosterone and androgen receptor serve an important role in male reproduction. When the androgen receptor gene is knocked out, testosterone secretion is reduced, testis is markedly atrophied, spermatogenesis is blocked in pre-meiotic diploid phase and spermatozoa are hardly detected in the epididymis. Infertility may occur in mice, and serum testosterone concentrations in mice are reduced when infertility occurs (25). Cholesterol undergoes a series of reactions in testicular stromal cells to produce certain crucial compounds that are associated with testosterone synthesis, including luteinizing hormone receptor (LHR) and 17 $\alpha$-hydroxylase (20). Furthermore, nitric oxide (NO) is an important second messenger. The half-life of NO is very short. Nitric oxide synthase (NOS) is a necessary enzyme in the process of NO synthesis. Therefore, the concentration of NOS is frequently used to indirectly represent the level of NO (26). This has been reported to affect testosterone biogenesis and sperm production when expressed in testicular stromal cells (27-31). Previous studies have suggested that the content of NO in infertile sperm is associated with the germ cell apoptosis rate $(32,33)$. These results also indirectly suggested that an increased amount of NO may enhance the ability of antioxidant damage and fight against the damage of harmful factors to germ cells or other cells in the process of cadmium induced male infertility. Additionally, excessive NO may be a prerequisite for oxidative stress, since excessive NO causes semen nitrification stress reaction, and eventually male infertility $(32,34)$. However, it remains unclear whether NO is involved in cadmium toxicity in testicular stromal cells or whether its role is associated with LHR and $17 \alpha$-hydroxylase. Subsequently, the present study aimed to investigate the mechanisms of cadmium-induced reproductive toxicity.

\section{Materials and methods}

Materials, equipment and reagents. The present study used an upright light microscope (Olympus Corporation) and a chemiluminescence imager (Tanon Science and Technology Co., Ltd.). In addition, the current study utilized various reagents as follows: LHR (Boster Biological Technology), $17 \alpha$-hydroxylase (Affinity, Inc.) endothelial NOS (eNOS; Affinity, Inc.), diaminobenzidine tetrahydrochloride (DAB) kit (Origene Technologies, Inc.), streptavidin-biotin complex immunohistochemical kit (Fuzhou Maixin Biotech Co., Ltd.), terminal deoxynucleotidyl transferase dUTP nick end labeling (TUNEL) apoptosis kit (Roche Diagnostics), mouse androgen ELISA kit (cat. no. E03A0019; BlueGene Biotech Co., Ltd.) and cadmium chloride (analytical purity; Sinopharm Chemical Reagent Co., Ltd.).

Animal grouping. A total of 24 Institute of Cancer Research male specific pathogen-free mice with an average weight of $23 \mathrm{~g}$ were obtained from Hunan SJA Laboratory Animal Co., Ltd. (Hunan, China) and housed in the Animal Experimental Center of Guilin Medical College. All experiments were approved by the Ethical Committees of Guilin Medical University (Guilin, China). All mice were housed at a controlled temperature of $25^{\circ} \mathrm{C}, 55-65 \%$ humidity and with a 12-h light/dark cycle. The food and water provided were sterilized and mice had free access to food and water. Mice were randomly divided into four groups as determined by preliminary experiments (Fig. 1; n=6 animals/group), including the normal control group (gavage-fed with saline), the low-concentration cadmium toxicity group [fed with $2 \mathrm{mg} / \mathrm{kg}$ (BW) cadmium], the medium-concentration cadmium toxicity group (fed with $4 \mathrm{mg} / \mathrm{kg}$ BW cadmium) and the high-concentration cadmium toxicity group (fed with $8 \mathrm{mg} / \mathrm{kg} \mathrm{BW}$ cadmium). Gavage was performed once per day for 8 consecutive weeks and the volume administration each time was $\leq 0.2 \mathrm{ml}$. Mice were subsequently sacrificed by cervical dislocation and according to the guidelines given in 'The Laboratory Mouse' (35). A midline incision was made on the abdomen using a scalpel, and the organs and testicular tissues were identified and removed. One half of the tissue was paraffin embedded for immunohistochemistry and the other half was frozen for subsequent protein analysis. In addition, blood samples were taken to determine androgen levels.

Immunochemical detection. Testicular tissues were fixed with $10 \%$ neutral formaldehyde for $48 \mathrm{~h}$ at room temperature and paraffin-embedded, sectioned, heated to $60^{\circ} \mathrm{C}$, dewaxed in xylene and rehydrated (alcohol series, 100, 95, 85 and 75\%). Subsequently, they were washed in PBS for $5 \mathrm{~min}$. Sections (4- $\mu \mathrm{m}$ thick) were subsequently incubated with $3 \%$ hydrogen peroxide at room temperature for $30 \mathrm{~min}$. Sections were incubated with mouse monoclonal primary antibodies against eNOS (cat. no. ab76198; 1:100; Abcam), LHR (cat. no. RPU51114; 1:250; OriGene Technologies, Inc.) and $17 \alpha$-hydroxylase (cat. no. RPU51114; 1:250; Biomatik) overnight at $4^{\circ} \mathrm{C}$. The sections were then incubated with secondary antibodies [undiluted; cat. no. PV-6000; Universal kit (mouse/rabbit polymer detection system); cat. no. PV-6000; OriGene Technologies, Inc.] for $30 \mathrm{~min}$ at room temperature. Sections were subsequently incubated with DAB and stained with hematoxylin and eosin $(\mathrm{H} \& \mathrm{E})$. Hematoxylin staining was performed for $2 \mathrm{~min}$ at room temperature, and eosin staining was performed for $30 \mathrm{sec}$ at room temperature. The sections were dehydrated, clarified and mounted. Images were captured with an upright light microscope (magnification, x400) and analyzed using AxioVision software (version 4.8.2; Carl Zeiss AG). Two independent pathologists evaluated the slides. The immunostaining intensity was scored as $0,1,2$ and 3 for negative, weak, moderate and strong staining, respectively. In addition, immunoreactivity was scored as follows: Strong (3), moderate (2), mild (1) or negative (0) for $>60,21-60,5-20$ or $<5 \%$ stained cells, respectively. 


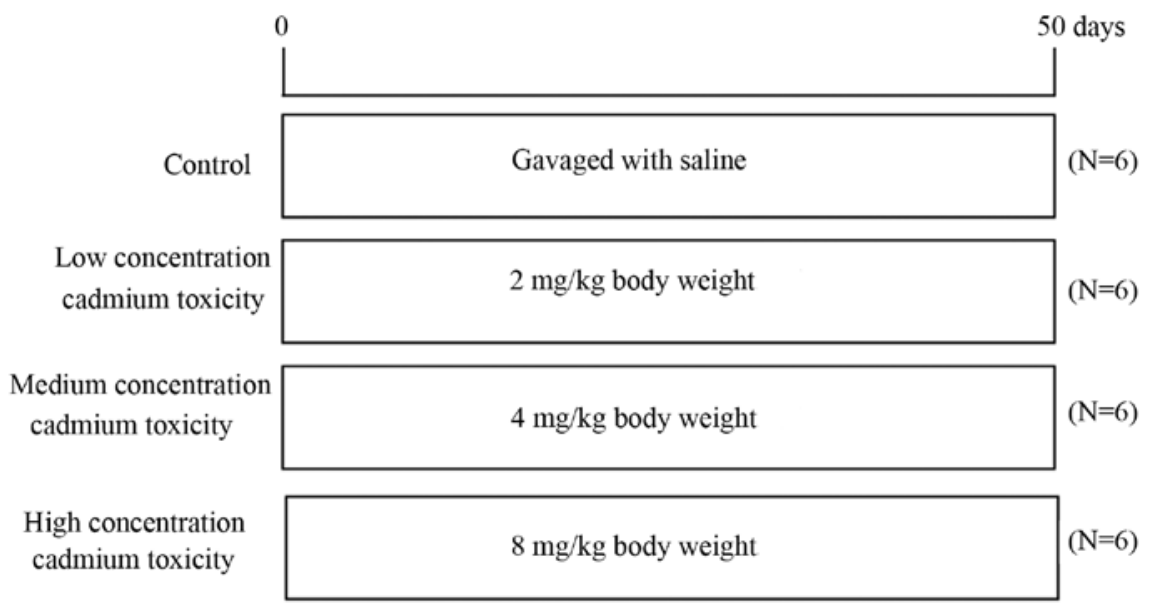

Figure 1. Experiment protocol used in the present study.

Western blotting. Proteins were extracted from testicular tissues using RIPA buffer (Beijing Solarbio Science \& Technology Co., Ltd.). Protein concentration was determined using a Bicinchoninic Acid Protein Concentration Assay kit (Enhanced) purchased from Beyotime Institute of Biotechnology (cat. no. P0010S). Proteins (20 $\mu \mathrm{g} / \mathrm{lane})$ were separated by $10 \%$ SDS-PAGE and transferred onto a nitrocellulose membrane. Membranes were blocked in 5\% non-fat milk in TBS with $0.05 \%$ Tween-20 for $2 \mathrm{~h}$ at room temperature. Membranes were incubated with mouse monoclonal primary antibodies against eNOS, LHR and $17 \alpha$-hydroxylase as aforementioned, and $\beta$-actin (cat. no. TA-09; 1:1,000; OriGene Technologies, Inc.) at room temperature for $2 \mathrm{~h}$ and $4^{\circ} \mathrm{C}$ overnight. Membranes were then incubated with the goat anti-mouse IgG-horseradish peroxidase (HRP; cat. no. sc-2004; 1:5,000; Santa Cruz Biotechnology, Inc.) and goat anti-rabbit IgG-HRP (cat. no. sc-2005; 1:2,000 Santa Cruz Biotechnology, Inc.) secondary antibodies at $37^{\circ} \mathrm{C}$ for $1 \mathrm{~h}$. Enhanced chemiluminescence reagent (SuperSignal West Femto Substrate Trial kit; cat. no. D046; Bridgen Biotech Co., Ltd.) was used to detect the signal on the membrane and images were captured using the Bio-Rad Gel Image Chemidoc ${ }^{\mathrm{TM}}$ XRS system (Bio-Rad Laboratories, Inc.). The data were analyzed via densitometry using Bio-Rad Image Lab software (version 6.0.1; Bio-Rad Laboratories, Inc.) and normalized to the expression of the internal control ( $\beta$-actin).

Determination of testis cell apoptosis with the TUNEL assay. Mice testis cell apoptosis was assessed by TUNEL assay (Roche Diagnostics) (36). Sections were fixed in 4\% paraformaldehyde for $20 \mathrm{~min}$ at room temperature. Paraffin-embedded sections were dewaxed in xylene and rehydrated using an ethanol gradient $(100,100,95,85$ and $75 \%)$. Sections were incubated with proteinase $\mathrm{K}$ at $37^{\circ} \mathrm{C}$ for $30 \mathrm{~min}$ and with $3 \%$ hydrogen peroxide at $37^{\circ} \mathrm{C}$ for $10 \mathrm{~min}$ and washed with PBS. Section were incubated with $50 \mu 1$ TUNEL assay substrate at $37^{\circ} \mathrm{C}$ in the dark for $1 \mathrm{~h}$. Sections were washed with PBS and incubated with $50 \mu \mathrm{l}$ converter-POD (included in the TUNEL kit) at $37^{\circ} \mathrm{C}$ for $30 \mathrm{~min}$. Sections were then washed with PBS and treated with DAB for color development. Sections were observed under an upright light microscope (magnification, $\mathrm{x} 400$ ) and particles with brown or yellow nuclei were considered as positively stained and counted. At least three fields were analyzed for each mouse. Sections were graded according to the percentage of positive cells as follows: Strong (3), moderate (2), mild (1) or negative (0) for $>60,21-60$, $5-20$ or $<5 \%$ stained cells.

Determination of serum androgen levels in mice. Following mice sacrifice, $0.8 \mathrm{ml}$ blood was collected from the heart. Blood was placed on ice for $30 \mathrm{~min}$ and centrifuged at $1,000 \mathrm{~g} / \mathrm{min}$ for $20 \mathrm{~min}$. The resulting supernatant was obtained and stored at $-20^{\circ} \mathrm{C}$. Androgen levels were determined using an ELISA kit. The ELISA assay was conducted according to the manufacturer's protocol. Briefly, the blood sample was first brought to room temperature. Following standard product preparation and sample addition, the antibody was added for $1 \mathrm{~h}$ at $37^{\circ} \mathrm{C}$. Subsequent to washing, $\mathrm{A}$ and $\mathrm{B}$ agent were gently agitated for blending, followed by incubation at $37^{\circ} \mathrm{C}$ in the dark for $6 \mathrm{~min}$. Termination solution was added and measurements were taken sequentially at a wavelength of $450 \mathrm{~nm}$.

Statistical analysis. SPSS 18.0 software (SPSS, Inc.) was used for statistical analysis. Data are expressed as the mean \pm standard deviation. One-way ANOVA followed by Fisher's least significant difference test was used for comparison between the experimental groups and the control group.

\section{Results}

Effect of cadmium on mice weight and serum androgen level. There was no significant difference identified between the body weights of mice in the experimental and control groups ( $\mathrm{P}>0.05$; Fig. 2A). In addition, mice from the low and medium groups demonstrated higher androgen concentrations compared with the control group and the low-cadmium group $(2 \mathrm{mg})$ presented the highest androgen concentration $(\mathrm{P}<0.05$; Fig. 2B).

Influence of cadmium on testicular morphology and apoptosis. As presented in Fig. 3A, H\&E staining demonstrated that mice from the control group presented testicular morphological characteristics indicative of sexual maturity as follows: i) Testicular seminiferous tubules with thick walls; ii) spermatogenic 

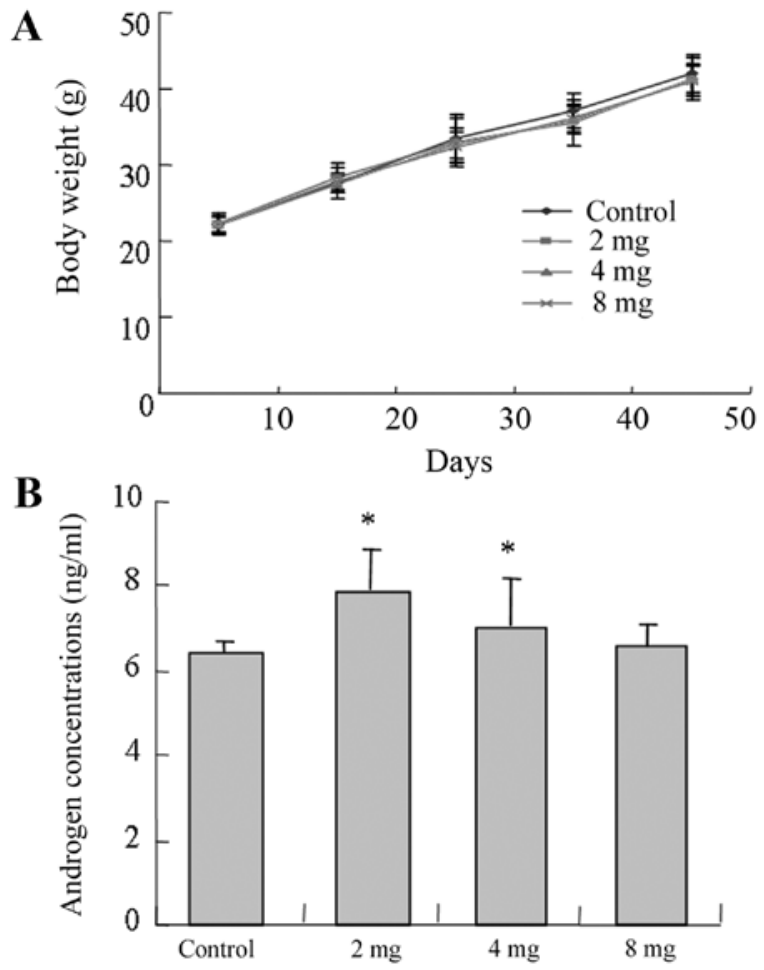

Figure 2.Body weight and serum androgen levels of mice in the different groups. (A) Body weights of the four groups of mice. (B) Serum androgen levels of the four groups of mice. The four groups were as follows: Normal control group (gavage-fed with saline); low-concentration cadmium toxicity group $(2 \mathrm{mg} / \mathrm{kg}$ body weight); medium-concentration cadmium toxicity group ( $4 \mathrm{mg} / \mathrm{kg}$ body weight); and high-concentration cadmium toxicity group ( $8 \mathrm{mg} / \mathrm{kg}$ body weight). Data is presented as the mean \pm standard deviation. ${ }^{*} \mathrm{P}<0.05$ vs. control group.

cells and support cells at various developmental stages with swirling contours and on thickened spermatogenic epithelia; iii) sperm cells in the seminiferous tubules; and iv) plump testicular stromal cells. By contrast, mice in the low-cadmium group demonstrated decreased thickness of the testicular seminiferous tubule walls, less apparent swirling contours and no obvious changes in the appearance of testicular stromal cells. However, sperm cells were observed on the walls of the seminiferous tubules. Mice in the medium-cadmium group presented the following features: i) A thin germinal epithelium; ii) sporadic bleeding in the testicular stroma; iii) cells with aberrant swirling contours; and iv) decreased spermatogenesis. Mice from the high-cadmium group exhibited the following features: i) A very thin germinal epithelium; ii) seminiferous tubules with aberrant morphology; iii) a markedly low level of normal spermatogenesis; iv) no swirling contours; v) apparent abnormalities of the testicular stroma (stromal vacancy); and vi) spots of bleeding. The expression levels of LHR and $17 \alpha$-hydroxylase were higher in the low groups compared with in the control groups $(\mathrm{P}<0.05)$, but less high in the high cadmium group ( $\mathrm{P}>0.05)$. eNOS and $17-\alpha$-hydroxylase exhibited consistent alterations. The low-cadmium group and the medium-cadmium group exhibited higher expression levels than the control group, while the expression levels in the high-cadmium group were slightly lower. eNOS expression was the highest in the medium-cadmium group and relatively low in the low-cadmium group (Fig. 3A and C; Table I). In addition, the number of TUNEL-positive nuclei significantly increased with cadmium in a concentration-dependent manner, which suggested elevated apoptosis rates (Fig. 3B and C; Table I).

Influence of cadmium on protein levels in testicular tissue. The expression levels of LHR, 17 $\alpha$-hydroxylase and eNOS were altered following the administration of different concentrations of cadmium. Notably, the levels of LHR, $17 \alpha$-hydroxylase and eNOS were increased in the low- and medium-cadmium groups, whereas they were significantly decreased in the high-cadmium group compared with the control group (Fig. 4; 17- $\alpha$-hydroxylase control vs. low-/medium-/high-cadmium, $\mathrm{P}<0.05 /<0.05 /<0.01$; LHR control vs. low-/medium-/high-cadmium, $\mathrm{P}<0.05 /<0.05 /<0.05$; eNOS control vs. low-/medium-/high-cadmium, $\mathrm{P}<0.05 /<0.05 /<0.01)$.

\section{Discussion}

The present study investigated the impact of intragastric administration of cadmium on mice testicular features. There was no significant difference identified in body weight between the experimental and control groups. Cadmium dose and drug delivery time may have affected the digestive system in mice, although these factors were not taken into consideration. Alternatively, perhaps due to the gavage time not being of a sufficiently long duration, the observed cadmium dose-effect differences were small and consequently no major effects were observed in the BW of the mice. The histopathological results demonstrated that the high-dose of cadmium induced seminiferous tubule wall thinning, an increase in interstitial hyperemia level, and lower numbers of sertoli and sperm cells. These findings suggest that the blood-testis barrier in the mice may have been destroyed, since the mice in the low-dose group exhibited no changes. A previous study also demonstrated that mice exposure to low doses of cadmium does not cause any physiological processes disorder, whereas exposure to higher doses of cadmium affects the autoimmune reaction of testicular tissue and leads to microcirculation impairment, blood-testis barrier damage, which therefore disturb spermatogenesis (37). The TUNEL results also demonstrated that apoptosis was significantly higher in all cadmium-treated groups compared with the control group.

Gonadotropin regulates testosterone synthesis by Leydig cells through the gonadal axis and testosterone stimulates spermatogenesis by binding to the androgen receptor (38-40). The two key factors involved in testosterone synthesis by Leydig cells are LHR and $17 \alpha$-hydroxylase. In the present study, the results from ELISA and immunochemistry demonstrated that these two proteins were highly expressed in the low- and medium-dose cadmium groups compared with the control group. In addition, the low-dose group exhibited the highest level of serum androgen. These results indicate that, in the low- and medium-cadmium groups, the gonadal axis of the body regulates testosterone synthesis. Furthermore, the synthesis of testosterone can be completed through feedback mechanisms (41). The present results also indicate that medium levels of cadmium may promote androgen synthesis in males. It has been reported that exposure to low doses of 
A
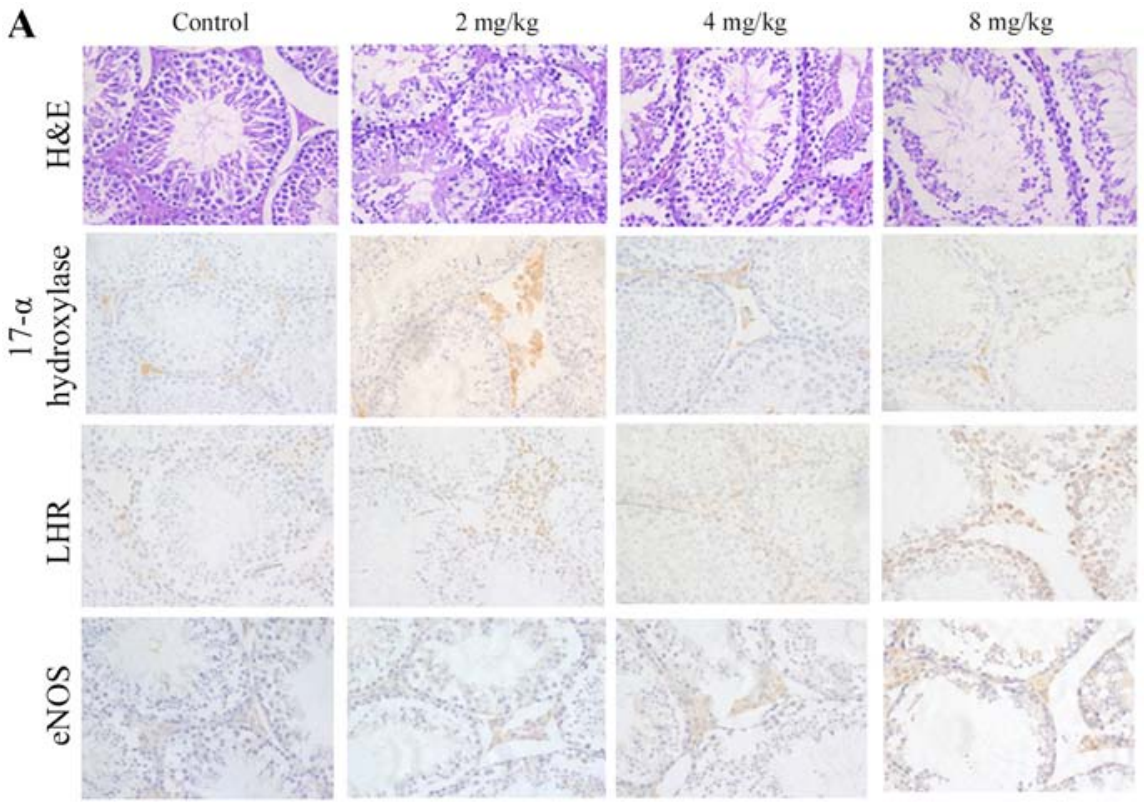

B
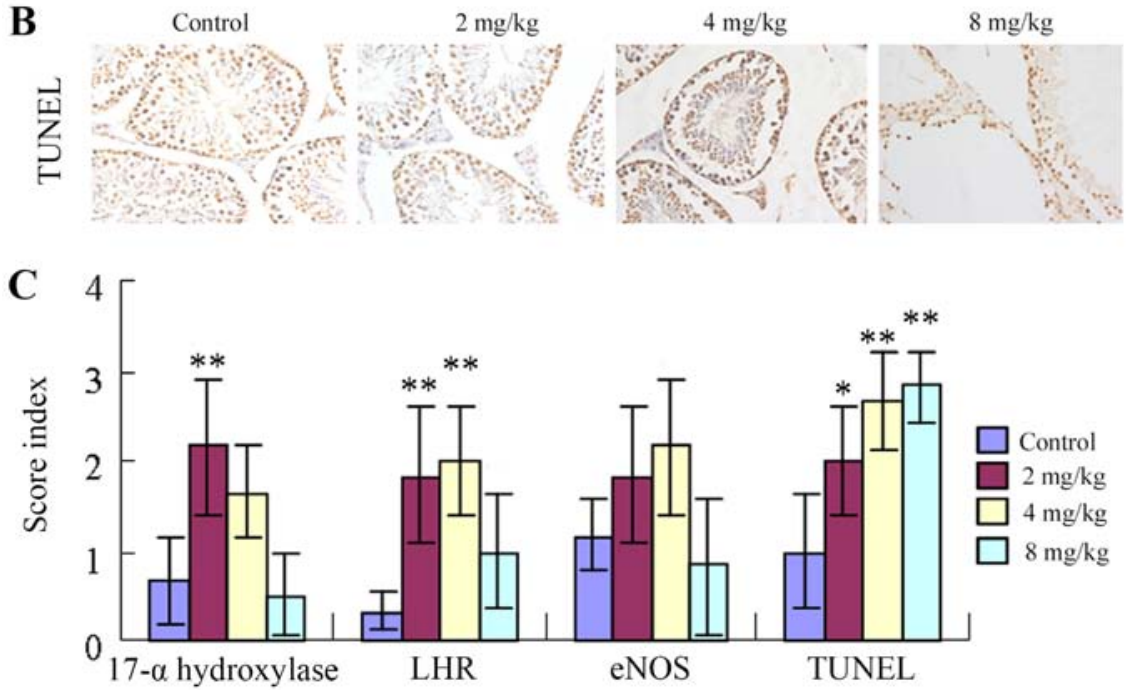

Figure 3. Influence of cadmium on testicular tissue protein levels and apoptosis of testicular cells. (A) H\&E staining revealed testicular morphology. Immunohistochemical staining demonstrated that the testicular morphology and expression levels of LHR, 17 $\alpha$-hydroxylase and eNOS were altered in testicular tissues following administration of different concentrations of cadmium. Magnification, $\mathrm{x}$ 400. (B) The effect of cadmium on testicular cell apoptosis was measured by the TUNEL assay. The number of TUNEL-positive nuclei following cadmium treatment was increased in a concentration-dependent manner, which indicated elevated rates of apoptosis. Magnification, x400. (C) Expression levels of LHR, 17 $\alpha$-hydroxylase, eNOS and TUNEL in testicular tissues following administration of different concentrations of cadmium. Data are presented as the mean \pm standard deviation. ${ }^{*} \mathrm{P}<0.05,{ }^{* *} \mathrm{P}<0.01$ vs. control group. eNOS, endothelial nitric oxide synthase; LHR, luteinizing hormone receptor; TUNEL, terminal deoxynucleotidyl transferase dUTP nick end labeling; H\&E, hematoxylin and eosin.

cadmium may increase the androgen level in males (42-44). It is possible that there is a critical point between the medium and high concentrations of cadmium beyond which the compensatory activities of androgen cannot keep the testicular structure intact. The current results demonstrated that at a high cadmium concentration, the testicular structure was severely impaired to a degree that may have been beyond the body's ability to compensate. Furthermore, the expression levels of serum androgen and proteins were decreased in the high concentration group. What factors are involved in a compensatory mechanism requires further investigation.

In addition, results from the present study demonstrated that eNOS was positively expressed in testicular cells and that eNOS expression level was the highest in the medium-dose cadmium group. NO is an important effector molecule in the regulation of spermatogenesis. A large quantity of NO has been reported to exert toxic effects in sperm, whereas lower concentrations of NO are conducive to fertility and spermatogenesis $(45,46)$. The present study revealed that the highest eNOS levels were observed in the medium-cadmium concentration group, and the serum androgen levels were highest in the low- and medium-cadmium groups. These results suggest that NO may be a downstream messenger that affects testosterone synthesis or a stress-response molecule in the compensatory mechanism of testosterone synthesis. According to the results of the present study, the peak of eNOS was later than that of serum androgen concentration. The former appeared in the medium concentration group, the latter appeared in the low concentration group, and the increase in NO concentration in this feedback mechanism was lagging behind the synthesis 
Table I. Expression levels of LHR, 17 $\alpha$-hydroxylase, eNOS and TUNEL in testicular tissues.

\begin{tabular}{lcccc}
\hline Group & 17 - $\alpha$-hydroxylase & LHR & eNOS & TUNEL \\
\hline Control & $0.67 \pm 0.47$ & $0.33 \pm 0.18$ & $1.17 \pm 0.41$ & $1.00 \pm 0.63$ \\
$2 \mathrm{mg} / \mathrm{kg}$ & $2.17 \pm 0.75^{\mathrm{b}}$ & $1.83 \pm 0.75^{\mathrm{b}}$ & $1.83 \pm 0.75$ & $2.00 \pm 0.63^{\mathrm{a}}$ \\
$4 \mathrm{mg} / \mathrm{kg}$ & $1.67 \pm 0.52$ & $2.00 \pm 0.63^{\mathrm{b}}$ & $2.17 \pm 0.75$ & $2.67 \pm 0.52^{\mathrm{b}}$ \\
$8 \mathrm{mg} / \mathrm{kg}$ & $0.50 \pm 0.45$ & $1.00 \pm 0.63$ & $0.83 \pm 0.75$ & $2.83 \pm 0.41^{\mathrm{b}}$ \\
\hline
\end{tabular}

${ }^{\mathrm{a}} \mathrm{P}<0.05$, ${ }^{\mathrm{P}} \mathrm{P}<0.01$ vs. control group. eNOS, endothelial nitric oxide; LHR, luteinizing hormone receptor; TUNEL, terminal deoxynucleotidyl transferase dUTP nick end labeling.

A
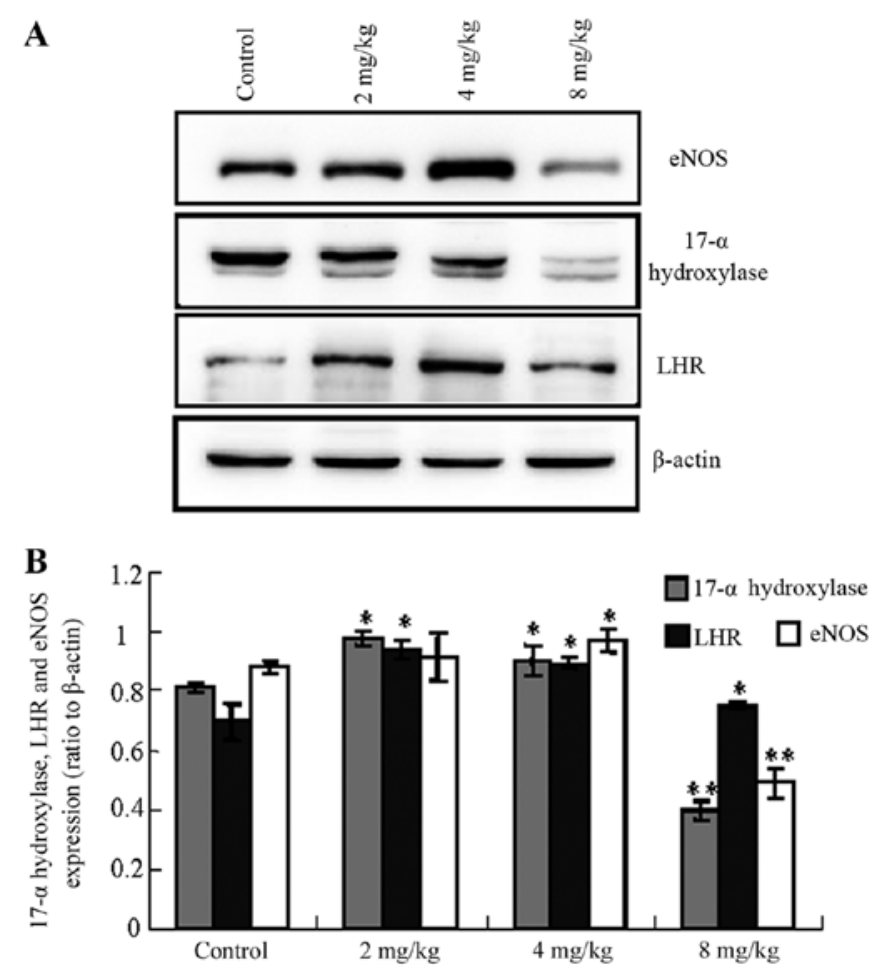

Figure 4. Influence of cadmium on Leydig cell protein expression levels determined by western blotting. (A) Expression levels of LHR, 17 $\alpha$-hydroxylase and eNOS were altered in testicular tissues following administration of different concentrations of cadmium. (B) Quantification of the expression levels of LHR, $17 \alpha$-hydroxylase and eNOS in testicular tissues following administration of different concentrations of cadmium. Data are presented as the mean \pm standard deviation. ${ }^{*} \mathrm{P}<0.05,{ }^{* *} \mathrm{P}<0.01$ vs. corresponding control group. eNOS, endothelial nitric oxide synthase; LHR, luteinizing hormone receptor.

of androgen. This may explain the delayed peak in NO levels with respect to cadmium levels. Furthermore, cadmium toxicity is associated with increased blood pressure (47). NO is a vasodilation factor that stimulates the relaxation of endothelium-smooth muscle cells, participating therefore in the regulation of vascular function (48). In the present study, the observation that eNOS was at its highest levels in the medium-cadmium group was not compatible with the expression profile of the two testosterone synthesis enzymes. One possibility is that at the high cadmium concentrations, the mice experienced elevated blood pressure as well as NO synthesis; NO can relax blood vessels to antagonize the increased blood pressure. As higher levels of NO stimulate relaxation of the

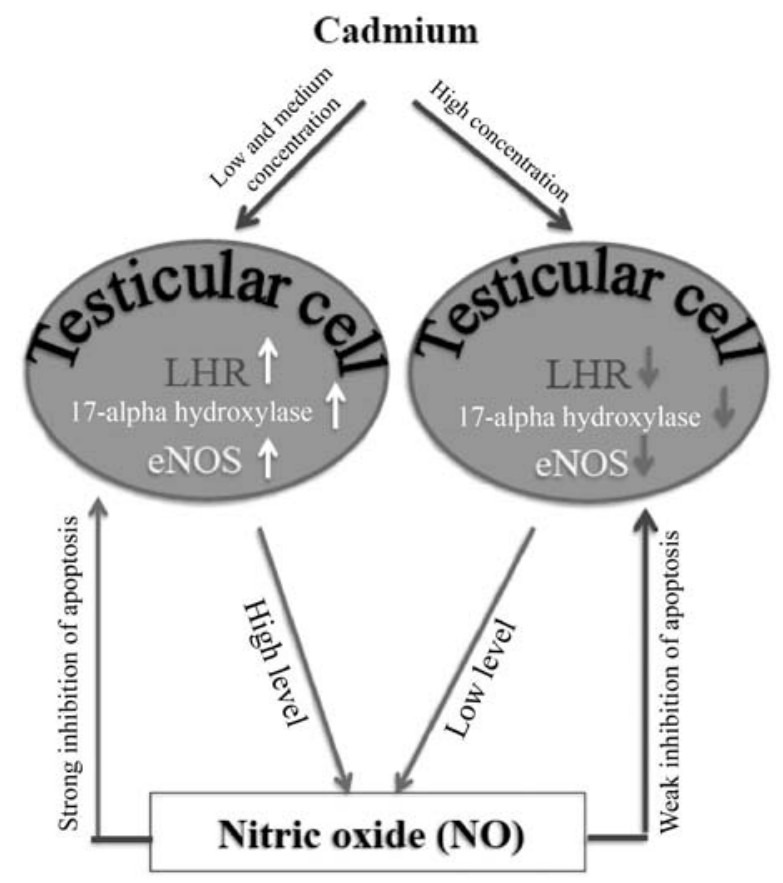

Figure 5. Schematic model of the potential role of cadmium on testicular injury. In the present study, LHR, 17 $\alpha$-hydroxylase and eNOS levels were revealed to be elevated in the low and medium dose groups. Their levels were low in the high dose group. Expression levels of LHR and $17 \alpha$-hydroxylase were consistent and were higher in the low and medium dose groups compared with in the control group. eNOS expression was the highest in the medium dose group. The increased expression levels of LHR, 17 $\alpha$-hydroxylase and eNOS in the low and medium dose groups may inhibit the apoptosis of testicular cells caused by cadmium. The decreased expression levels of all factor in the high dose group may be the result of the increased apoptosis of testicular cells. eNOS, endothelial nitric oxide synthase; LHR, luteinizing hormone receptor; NO, nitric oxide.

blood vessels, an additional input of energy would be required to maintain the body's blood pressure. Alternatively, a medium dose of cadmium was capable of leading to the destruction of a large number of Leydig cells. To facilitate the functionality of the remaining testicular stromal cells, a higher expression level of NO, leading to blood vessel dilation, would ensure increased delivery of oxygen and nutrients to the cells and/or extraction of metabolic waste.

In conclusion, up to medium concentration trace amounts of cadmium had no effect on the testicular structure of male mice, although the number of apoptotic cells was increased. However, increased doses of cadmium induced testicular structure damage. The results from the present study also revealed 
that cadmium toxicity altered the expression levels of LHR and $17 \alpha$-hydroxylase in testicular cells, which may alter testosterone synthesis. In addition, based on the results of the present study, one may hypothesize that NO was involved in the repair or compensation mechanism(s) following cadmium-induced testicular injury and this effect was mediated by eNOS expression regulation in Leydig cells (Fig. 5). Future study should investigate whether other interconnected signaling pathways are involved in this compensation mechanism. Due to limited funds, the present study did not investigate the effect of relevant drugs on cadmium-induced testicular injury. Therefore, future studies should focus on this aspect.

\section{Acknowledgements}

Not applicable.

\section{Funding}

This study was supported by the Guangxi Natural Science Foundation Project (grant no. 2016 GXNSFAA 380319) and the Guilin Scientific Research and Technology Development project (grant no. 20130120-8).

\section{Availability of data and materials}

The datasets used and/or analyzed during the current study are available from the corresponding authors on reasonable request.

\section{Authors' contributions}

YR, WS, LJZ, WZ, HQ, YH, DL, CM, SZ and LZ were responsible for research creation and design, data acquisition, analysis and interpretation of data, statistical analysis, manuscript drafting, and critical revision of the manuscript for important intellectual content. All authors read and approved the final version of manuscript.

\section{Ethics approval and consent to participate}

All experiments were approved by the Ethical Committees of Guilin Medical University (Guilin, China).

\section{Patients consent for publication}

Not applicable.

\section{Competing interests}

The authors declare that they have no competing interests.

\section{References}

1. Vandenberg LN, Colborn T, Hayes TB, Heindel JJ, Jacobs DR Jr Lee DH, Shioda T, Soto AM, vom Saal FS, Welshons WV, et al: Hormones and endocrine-disrupting chemicals: Low-dose effects and nonmonotonic dose responses. Endocr Rev 33: 378-455, 2012

2. Medina MF, Arrieta MC, Villafañe MN, Klyver SMR, Odstrcil IMA and González ME: Early signs of toxicity in testes and sperm of rats exposed to low cadmium doses. Toxicol Ind Health 33: 576-587, 2017.
3. Akinloye O, Arowojolu AO, Shittu OB and Anetor JI: Cadmium toxicity: A possible cause of male infertility in Nigeria. Reprod Biol 6: 17-30, 2006.

4. Luevano $\mathrm{J}$ and Damodaran C: A review of molecular events of cadmium-induced carcinogenesis. J Environ Pathol Toxicol Oncol 33: 183-194, 2014.

5. Niknafs B, Salehnia M and Kamkar M: Induction and determination of apoptotic and necrotic cell death by cadmium chloride in testis tissue of mouse. J Reprod Infertil 16: 24-29, 2015.

6. De Angelis C, Galdiero M, Pivonello C, Salzano C, Gianfrilli D, Piscitelli P, Lenzi A, Colao A and Pivonello R: The environment and male reproduction: The effect of cadmium exposure on reproductive function and its implication in fertility. Reprod Toxicol 73: 105-127, 2017

7. Marettoá E, Maretta M and Leqáth J: Toxic effects of cadmium on testis of birds and mammals: A review. Anim Reprod Sci 155: $1-10,2015$.

8. Verqilio CS, Moreira RV, Carvalho CE and Melo EJ: Evolution of cadmium effects in the testis and sperm of the tropical fish Gymnotus carapo. Tissue Cell 47: 132-139, 2015.

9. Yang Q, Li P, Wen Y, Li S, Chen J, Liu X, Wang L and Li X: Cadmium inhibits lysine acetylation and succinylation inducing testicular injury of mouse during development. Toxicol Lett 291: 112-120, 2018.

10. Ali I, Damdimopoulou P, Stenius U, Adamsson A, Mäkelä SI, Åkesson $\mathrm{A}$, Berglund $\mathrm{M}$, Håkansson $\mathrm{H}$ and Halldin $\mathrm{K}$ : Cadmium-induced effects on cellular signaling pathways in the liver of transgenic estrogen reporter mice. Toxicol Sci 127: 66-75, 2012.

11. Schneider SN, Liu Z, Wang B, Miller ML, Afton SE, Soleimani M and Nebert DW: Oral cadmium in mice carrying 5 versus 2 copies of the Slc39a8 gene: Comparison of uptake, distribution, metal content, and toxicity. Int J Toxicol 33: 14-20, 2014.

12. Hu H, Lu X, Cen X, Chen X, Li F and Zhong S: RNA-Seq identifies key reproductive gene expression alterations in response to cadmium exposure. Biomed Res Int 2014: 529271, 2014.

13. Angenard G, Muczynski V, Coffigny H, Pairault C, Duquenne C, Frydman R, Habert R, Rouiller-Fabre V and Livera G: Cadmium increases human fetal germ cell apoptosis. Environ Health Perspect 118: 331-337, 2010

14. Singh KP, Kumari R, Pevey C, Jackson D and DuMond JW: Long duration exposure to cadmium leads to increased cell survival, decreased DNA repair capacity, and genomic instability in mouse testicular Leydig cells. Cancer Lett 279: 84-92, 2009.

15. Ji YL, Wang H, Zhao XF, Wang Q, Zhang C, Zhang Y, Zhao M, Chen YH, Meng XH and Xu DX: Crosstalk between endoplasmic reticulum stress and mitochondrial pathway mediates cadmium-induced germ cell apoptosis in testes. Toxicol Sci 124: 446-459, 2011

16. Oliveira H, Lopes T, Almeida T, Pereira Mde L and Santos C: Cadmium-induced genetic instability in mice testis. Hum Exp Toxicol 31: 1228-1236, 2012.

17. Veeriah V, Saran U, Swaminathan A, Balaguru UM, Thangaraj P, Nagarajan S, Rajendran VK and Chatterjee S: Cadmium-induced embryopathy: Nitric oxide rescues teratogenic effects of Cadmium. Toxicol Sci 144: 90-104, 2015.

18. Seid Alian N, Khodarahmi P and Naseh V: The effect of cadmium on apoptotic genes mRNA expression of Bax and Bcl-2 in small intestine of rats. Iran J Pathol 13: 408-414, 2018.

19. Breton J, Le Clère K, Daniel C, Sauty M, Nakab L, Chassat T, Dewulf J, Penet S, Carnoy C, Thomas P, et al: Chronic ingestion of cadmium and lead alters the bioavailability of essential and heavy metals, gene expression pathways and genotoxicity in mouse intestine. Arch Toxicol 87: 1787-1795, 2013.

20. Uno Y, Hosaka S and Yamazaki H: Identification and analysis of CYP7A1, CYP17A1, CYP20A1, CYP27A1 and CYP51A1 in cynomolgus macaques. J Vet Med Sci 76: 1647-1650, 2014.

21. Chen H, Ge RS and Zirkin BR: Leydig cells: From stem cells to aging. Mol Cell Endocrinol 306: 9-16, 2009.

22. Ge R, Chen G and Hardy MP: The role of the Leydig cell in spermatogenic function. Adv Exp Med Biol 636: 255-269, 2008.

23. Smith LB and Walker WH: The regulation of spermatogenesis by androgens. Semin Cell Dev Biol 30: 2-13, 2014.

24. Rey RA, Musse M, Venara M and Chemes HE: Ontogeny of the androgen receptor expression in the fetal and postnatal testis: Its relevance on Sertoli cell maturation and the onset of adult spermatogenesis. Microsc Res Tech 72: 787-95, 2009.

25. Chang C, Chen YT, Yeh SD, Xu Q, Wang RS, Guillou F, Lardy H and Yeh S: Infertility with defective spermatogenesis and hypotestosteronemia in male mice lacking the androgen receptor in Sertoli cells. Proc Natl Acad Sci USA 101: 6876-6881, 2004. 
26. Zhang F and Liao L: Role and significance of nitric oxide neurochemical remodeling in lower urinary tract dysfunction after spinal cord injury. Chin J Urol: 33, 2012.

27. Ren YP, Sun L, Shao XY, Chen J, Xiong B and Nong LL: Expressions of eNOS and cytochrome P450 in the testis of sexually mature SD rats and their significance. Zhonghua Nan Ke Xue 15: 911-914, 2009 (In Chinese).

28. Lim KH, Ancrile BB, Kashatus DF and Counter CM: Tumour maintenance is mediated by eNOS. Nature 452: 646-649, 2008.

29. Alpcan S, Başar H, Aydos TR, Kul O, Kısa Ü and Başar MM: Apoptosis in testicular tissue of rats after vasectomy: Evaluation of eNOS, iNOS immunoreactivities and the effects of ozone therapy. Turk J Urol 40: 199-206, 2014.

30. Kondo Y, Ishikawa T, Yamaguchi K, Yada T and Fujisawa M: Oral administration of tetrahydrobiopterin attenuates testicular damage by reducing nitric oxide synthase activity in a cryptorchid mouse model. J Androl 29: 153-163, 2008.

31. Guo J, Jia Y, Tao SX, Li YC, Zhang XS, Hu ZY, Chiang N, Lue YH, Hikim AP, Swerdloff RS, et al: Expression of nitric oxide synthase during germ cell apoptosis in testis of cynomolgus monkey after testosterone and heat treatment. J Androl 30: 190-199, 2009.

32. Zheng LP, Zhu X, Yang L, et al: Analysis and correlation study of trace elements in blood and semen of male sterile patients. Mod Prev Med: 1464-1466, 2012.

33. Cheng DZ, Du AL, Li CS, et al: Scavenging of superoxide free radicals generated by autooxidation of pyrogallol with ginger extract. Chin Spices: 35-39, 2014.

34. Saito H, Good S, Sato S, Ito A, Ikumi Y, Tanaka S, Ida T, Fujii S, Akaike T and Shimokawa H: Important role of endothelial caveolin-1 in the protective role of endothelium-dependent hyperpolarization against nitric oxide-mediated nitrative stress in microcirculation in mice. J Cardiovasc Pharmacol 71: 113-126, 2018.

35. Vladimir K: Gross anatomy, anatomy and normative biology, The Laboratory Mouse second edition, Chapter 2.2: 145-149, 2012.

36. Ohtani K, Yanagiba Y, Ashimori A, Takeuchi A, Takada N, Togawa M, Hasegawa T, Ikeda M and Miura N: Influence of injection timing on severity of cadmium-induced testicular toxicity in mice. J Toxicol Sci 38: 145-150, 2013.

37. Ogawa Y, Itoh M, Hirai S, Suna S, Naito M, Qu N, Terayama H, Ikeda A, Miyaso H, Matsuno Y, et al: Cadmium exposure increases susceptibility to testicular autoimmunity in mice. J Appl Toxicol 33: 652-660, 2013.

38. Wu S, Chen Y, Fajobi T, DiVall SA, Chang C, Yeh S and Wolfe A Conditional knockout of the androgen receptor in gonadotropes reveals crucial roles for androgen in gonadotropin synthesis and surge in female mice. Mol Endocrinol 28: 1670-1681, 2014.
39. Denolet E, De Gendt K, Allemeersch J, Engelen K, Marchal K, Van Hummelen P, Tan KA, Sharpe RM, Saunders PT, Swinnen JV and Verhoeven G: The effect of a Sertoli cell-selective knockout of the androgen receptor on testicular gene expression in prepubertal mice. Mol Endocrinol 20: 321-334, 2006.

40. Welsh M, Saunders PT, Atanassova N, Sharpe RM and Smith LB: Androgen action via testicular peritubular myoid cells is essential for male fertility. FASEB J 23: 4218-4230, 2009

41. Iwasa T, Matsuzaki T, Yano K, Yanagihara R, Mayila Y and Irahara $\mathrm{M}$ : The effects of chronic testosterone administration on hypothalamic gonadotropin-releasing hormone regulatory factors (Kiss1, NKB, pDyn and RFRP) and their receptors in female rats. Gynecol Endocrinol 34: 437-441, 2018.

42. Telisman S, Colak B, Pizent A, Jurasović J and Cvitković P: Reproductive toxicity of low-level lead exposure in men. Environ Res 105: 256-266, 2007.

43. Meeker JD, Rossano MG, Protas B, Padmanahban V, Diamond MP, Puscheck E, Daly D, Paneth N and Wirth JJ: Environmental exposure to metals and male reproductive hormones: Circulating testosterone is inversely associated with blood molybdenum. Fertil Steril 93: 130-140, 2010.

44. Jurasović J, Cvitković P, Pizent A, Colak B and Telisman S: Semen quality and reproductive endocrine function with regard to blood cadmium in Croatian male subjects. Biometals 17: 735-743, 2004.

45. Weinberg JB, Doty E, Bonaventura J and Haney AF: Nitric oxide inhibition of human sperm motility. Fertil Steril 64: 408-413, 1995.

46. Hellstrom WJ, Bell M, Wang R and Sikka SC: Effect of sodium nitroprusside on sperm motility, viability, and lipid peroxidation. Fertil Steril 61: 1117-1122, 1994.

47. Prozialeck WC, Edwards JR, Nebert DW, Woods JM, Barchowsky A and Atchison WD: The vascular system as a target of metal toxicity. Toxicol Sci 102: 207-218, 2008.

48. Chen CA, Wang TY, Varadharaj S, Reyes LA, Hemann C, Talukder MA, Chen YR, Druhan LJ and Zweier JL: S-glutathionylation uncouples eNOS and regulates its cellular and vascular function. Nature 468: 1115-1118, 2010.

This work is licensed under a Creative Commons Attribution-NonCommercial-NoDerivatives 4.0 International (CC BY-NC-ND 4.0) License. 